\title{
Thermodynamic, Kinetic and Isotherm Study of 4- chloro-2-methyl Phenoxy Acetic Acid (MCPA) by (PV/S-g-3D-GO/N) from Aquatic Solutions
}

\section{Alireza Hajighasemkhan}

shahid beheshti university of medical science

Elham Moniri ( $\square$ aygoy703@yahoo.com )

Islamic Azad University

Lobat Taghavi

Islamic Azad University

Homayon Ahmad Panahi

islamic azad university

Amir Hessam Hassani

islamic university of medical science

\section{Research}

Keywords: adsorption isotherms, adsorption kinetics, adsorption thermodynamics, 3D adsorbents, 4chloro-2-methyl-phenoxy acetic acid

Posted Date: October 27th, 2020

DOI: https://doi.org/10.21203/rs.3.rs-95697/v1

License: (c) (1) This work is licensed under a Creative Commons Attribution 4.0 International License. Read Full License 


\section{Abstract}

\section{Background}

In this study removal efficiency of 4-chloro-2-methyl-phenoxy acetic acid (MCPA) by 3D polymer nanomagnetic (PV/S-g-3D-GO/N) was investigated.

\section{Methods}

The effects of operation parameters including adsorbent mass, influent flow rate and inlet concentration on the adsorption performance are investigated.

Results

Maximum adsorption capacity $(4.36 \mathrm{mg} / \mathrm{g})$ was achieved at optimum conditions ( $\mathrm{pH}: 3$, contact time: $300 \mathrm{~min}$, adsorbent dosage: $5 \mathrm{~g} / \mathrm{l}$ and temperature: $50^{\circ} \mathrm{C}$ ). Moreover, adsorption isotherm and kinetics were agreed with the Langmuir model $\left(R^{2}=0.997\right)$ and pseudo-second-order model $\left(R^{2}=0.999\right)$, respectively. Thermodynamic studies also show that adsorption process was spontaneous $(\Delta G<0)$ and endothermic $(\Delta \mathrm{H}>0)$.

Conclusion

According to removal efficiency $(100 \%)$, this adsorbent is an excellent alternative for removal herbicide in high temperature industry.

\section{Introduction}

Water is one of the most important and valuable substance in the worldwide. In addition, safety and availability of water are demanding task for suppliers in the society (1-3). Today, herbicides have been used widely in the agriculture industry to provide the enough food for the population(4). Among various types of herbicides, MCPA is one of the most common which have used to control broad leaf weeds in agricultural lands (5)\{Esrafily, $2018 \# 18$ \}. Phenoxy herbicides are highly soluble in water that will result in easily contaminate surface water body (6) and is detectable even in drinking water\{Dehghani, $2014 \# 16\}$. Several epidemiological studies have reported a different health risk of MCPA such as adverse effects on the endocrine system, liver and kidney toxicity (7-9). Moreover, carcinogenicity, teratogenic and mutagenic effects have been reported. The agronomic MCPA dosage is typically as high as 1-2.5 kg ha-1 so, MCPA has been classified as a potential groundwater contaminant by the U.S. Environmental Protection Agency (EPA). Based on the health problem, the remove of this contaminant from aquatic solutions is necessary(4). Previously, the removal efficiency of the several physical, chemical and biological methods such as coagulation, sedimentation, filtration, chemical oxidation and adsorption to herbicide from the water have been studied (10). However, between the various methods, adsorption known suitable method due to its advantage such as simple, low price, rapid reaction and selectivity(11). During the last years, novel materials such as nano particle and modified nano particles have attracted considerable interest as 
an adsorbent for removing contaminants from aquatic solution(12). However, magnetic nano particles are preferred for using in water treatment due to easily adsorbed and regeneration properties $(13,14)$. Therefore, modified nano particles by magnetic agent such as $\mathrm{Fe}_{3} \mathrm{O}_{4}$ can improve surface area, chemical activity, reduce unwanted particles accumulation and stability of the nano particle that lead to high efficiency adsorption properties. In the recent years, the application of various functioned group such as silica, gold, and polymers in modifying nano particle has been studied widely (15). Graphene-based nanoparticle have specific properties due to their large specific surface area and rich porous structure, and have been successfully employed as adsorbents of organic pollutants(16). Some functioned graphene are rather difficult to separate after the adsorption process so, adsorbents with magnetic nanoparticles are more preferable, because of its aforementioned group that can be purified and regenerated easier by using magnetic field techniques(12). In addition, superparamagnetic $\mathrm{Fe}_{3} \mathrm{O}_{4}$ nanoparticles (NPs) onto the graphene oxide is an excellent adsorption material due to its large specific surface area, high stability, abundant oxygen-containing functional groups on the surface, and convenient magnetic seperability (17). Over the last years, the adsorption efficiency of herbicides from aquatic solutions has been of particular interest and much work has been devoted to investigate effects of different parameter in adsorption efficiency $(18,19)$. Kersten et al. investigated the adsorption efficiency of MCPA by Geothit and showed that the latter forms via the sharing of the carbonyl oxygen between the MCPA carboxylate group and a single coordinated surface hydroxyl groups, releasing an $\mathrm{H}_{2} \mathrm{O}$ molecule(10). Similarly, Iglesias et.al examined the adsorption of MCPA on the surface of goethite and of humic acid-coated goethite and found that desorption of the anionic form of the pesticide on goethite fitted an S-type isotherm and the amount adsorbed increased as the ionic strength decreased and the $\mathrm{pH}$ of the medium decreased(20). Jensen et.al studied the interactive degradation kinetics of MCPA in the soil and found highly significant inverse relationships between the adsorption and mineralization of chemicals in soil, and also shows best correlations between degradation rates and Freundlich adsorption coefficients(21). Most of the existing literature, have been conducted using pure individual sorbent for removal MPCA from aquatic solution (22-24) and there exist few studies that have been carried out concerning novel and complex sanitized absorbent. Therefore, the present study was conducted to synthesize temperature sensitive 3D magnetic nanoparticles for the adsorption of MCPA herbicides from aquatic solution. More interestingly, the effective factors on the adsorption process were investigated. In addition, adsorption conditions optimized for evaluation isotherm, kinetics and thermodynamics of adsorption processes. Moreover, adsorbent regeneration, and the removal efficiency of the PV/S-g-3D-GO/N adsorbent in MPCA herbicides from real samples was evaluated

\section{Materials And Methods}

\subsection{Chemicals}

Graphene oxide was purchased from Sigma Aldrich and other material including 2,2'azobisisobutyronitrile (AIBN) and MCPA were purchased from Merck (Darmstadt, Germany).

\subsection{Instruments and characterization of the adsorbent}


Fourier transform infrared spectroscopy (FTIR, Spectrum Two, PerkinElmer, USA) was used to distinguish the functional agent in molecules. Nanoparticle size, crystal structure, magnetic properties, was characterized by energy dispersive x-ray spectroscopy (EDS) equipped with FE-SEM Detector (Oxford Instrument, England), Transmission electron microscopy (TEM), X-ray diffraction (Xpert-PRO, Pananalytical, England). Vibrating-sample magnetometer (VSM, LBKFB, Daghigh Kavir, Iran), Thermal gravimetric of nano particles was analyzed by Thermo Gravimetric Analysis (TGA, STA 1500 Rheometric scientific, Switzerland) in a range of $0-600^{\circ} \mathrm{C}$ at $10^{\circ} \mathrm{C} / \mathrm{min}$ heating rate in the air atmosphere. The MCPA concentration was measured by a UV-Vis spectrophotometer (UV/Vis, DR5000, HACH, Germany), The chromatographic separation was performed by High Performance Liquid Chromatography (HPLCKNUARE Co Germany). The chromatographic conditions included the using system with a $\mathrm{C}_{18}$ column (5 $\mu \mathrm{m}$ particles, $250 \mathrm{~mm}$ length, and $4.6 \mathrm{~mm}$ internal diameter) was calibrated and tested prior to injection of the samples. The mobile phase consisted of water: acetonitrile (1:1 ratio) and the flow rate was $0.5 \mathrm{~mL} / \mathrm{min}$. An injection volume of $20 \mu \mathrm{L}$ was injected manually, while the column temperature was set at $30^{\circ} \mathrm{C}$. After the injection, a UV detector 2600 at a wavelength of $283 \mathrm{~nm}$ was used to detect MCPA in the samples. The analysis time and retention time for MCPA peak were 10.00 min and 3.4 min, respectively. The detection limit of 2,4-D was $1 \mathrm{ng} / \mathrm{L}$. All experiments run according to ASTM(25).

\subsection{Synthesis of magnetic $\mathrm{Fe}_{3} \mathrm{O}_{4}$ nanoparticles}

Magnetic $\mathrm{Fe}_{3} \mathrm{O}_{4}$ nanoparticle were prepared by co-precipitation (CPT) methol(26) First, $5.4 \mathrm{~g} \mathrm{FeCl} 3.6 \mathrm{H}_{2} \mathrm{O}$, $2 \mathrm{~g} \mathrm{FeCl}_{2} \cdot 4 \mathrm{H}_{2} \mathrm{O}$, and $200 \mathrm{~mL}$ deionized water were added to a three-neck flask in a water bathroom. The mixture was stirred at $800 \mathrm{rpm}$ for $30 \mathrm{~min}$, then heated to $80^{\circ} \mathrm{C}$ and, stirred for an extra $30 \mathrm{~min}$ in nitrogen atmosphere. Next, $40 \mathrm{~mL}$ of ammonia solution (25\%) was added dropwise to the mixture solution to reach a $\mathrm{pH}$ of 11 and the formation of a black precipitate. The mixed solution was kept for $2 \mathrm{~h}$, then cooled down to room temperature, and placed in an ultrasonic bath for $7 \mathrm{~min}$. The final precipitate was separated from the solution by a 1T (Tesla) magnet at the bottom of the flask, washed two times with deionized water and ethanol separately, and dried in an oven at $70^{\circ} \mathrm{C}$ for $12 \mathrm{~h}$.

\subsection{D structure of $\mathrm{Fe}_{3} \mathrm{O}_{4}$ magnetic nanoparticle}

Solution of graphene oxide ( $2 \mathrm{mg} / \mathrm{L})$ was prepared and $\mathrm{pH}$ of the solution was adjusted to 11 . Then, $0.965 \mathrm{~g}$ of $\mathrm{Fe}_{3} \mathrm{O}_{4}$ "which was synthesized in the previous section" was added in an ultrasonic bath. Next, suspension was incubated in a water bath without stirring at $90^{\circ} \mathrm{C}$ for $6 \mathrm{~h}$. The formed precipitate was separated by $1 \mathrm{~T}$ magnet and washed by water several times. The product was kept at $-90^{\circ} \mathrm{C}$ for $1 \mathrm{~h}$ and subsequently in a vacuum freeze dryer at $-70^{\circ} \mathrm{C}$ for $24 \mathrm{~h}$

\subsection{Modification of 3D-GO surface}

Solution including of $\mathrm{Fe}_{3} \mathrm{O}_{4} @ \mathrm{GO}(2 \mathrm{~g})$, epichlorohydrine $(40 \mathrm{~mL}), \mathrm{NaOH}(60 \mathrm{~mL})$, and sodium borohydride $(1 \mathrm{~g})$ were mixed and stirred in a dark chamber for $24 \mathrm{~h}$ at room temperature $\left( \pm 15^{\circ} \mathrm{C}\right)$. The precipitate was 
washed by cool water several times and added to $50 \mathrm{~mL}$ of $\mathrm{Na}_{2} \mathrm{~S}(0.5 \mathrm{M})$ then, $50 \mathrm{~mL}$ of acetate buffer $(\mathrm{pH}: 5)$, was added and was shake on a stirrer at $40^{\circ} \mathrm{C}$ for $24 \mathrm{~h}$

\subsection{Polymer grafting}

The obtained precipitate was added to the solution which including ethanol $(50 \mathrm{~mL})$, styrene $(10 \mathrm{~mL}), \mathrm{n}$ vinylcaprolactam $(1 \mathrm{~g})$, and $0.1 \mathrm{~g}$ of azobisisobutyronitrile (AIBN). The mixture was refluxed in nitrogen atmosphere in a water bath at $65^{\circ} \mathrm{C}$ for $8 \mathrm{~h}$. The obtained precipitate was washed three times by ethanol and five times with water then was dried in an oven at $70^{\circ} \mathrm{C}$.

\subsection{Batch experiments}

Experiments were carried out on both synthetic and real sample that was sampled from Zebakenar, Gilan (as a real agricultural wastewater) and Hakimiyeh, Tehran Pars (as deep well water), Iran. The adsorption experiments were carried out with the different adsorption condition, including $\mathrm{pH}$ (2-8), contact time (2360 minutes), temperature $\left(30-50^{\circ} \mathrm{C}\right)$, adsorbent dosage $(0.1-7 \mathrm{mg} / \mathrm{L})$, and initial herbicide $(5-60 \mathrm{mg} / \mathrm{L})$ for determining the optimum adsorption process to remove MPCA herbicide. All of the selected rang was according previous published paper. The optimum adsorption conditions were obtained by varying each variable while others kept constants. Then, in each stage of the experiment the sorbent was separated by filtration with $0.45 \mu \mathrm{m}$ membrane filter and analyzed by using UV-Vis-A spectrophotometer for measuring MPCA concentration. Finally, the synthesized PV/S-g-3D-GO/N was used for removing MPCA from real agricultural wastewater and deep well water. Herbicide concentrations in real samples were measured by using high-performance liquid chromatography (HPLC). Langmuir, Freundlich, Temkin and RedlichPeterson models were used to determine the best adsorption isotherm models. The adsorption kinetics were studied by the pseudo-first-order, pseudo-second-order, and intraparticle diffusion equations. Equilibrium isotherm measurements were carried out by keeping the solution volume $(200 \mathrm{~mL})$ and the amount of PV/S-g-3D-GO/N the constant and varying the concentration of MPCA (V) in $250 \mathrm{~mL}$ Erlenmeyer flasks. The $\mathrm{pH}$ of the solutions was adjusted by adding $1.0 \mathrm{~mol} \mathrm{~L}^{-1}$ sodium hydroxide or $1.0 \mathrm{~mol} \mathrm{~L}^{-1}$ hydrochloride acid solutions. The equilibration (shaking) time was $300 \mathrm{~min}$ at room temperature. After that, sorbent was separated by filtration with $0.45 \mu \mathrm{m}$ membrane filter. The filtrate was analyzed for herbicide by UV-Vis-A spectrophotometer. The removal efficiency of the MPCA and the amount of adsorbed MPCA per gram adsorbent was calculated using equations 1 and 2 , respectively.

$$
\begin{aligned}
& R_{E}=\frac{C_{0}-C_{t}}{C_{0}} \times 100 \\
& q_{e}=\frac{\left(C_{0}-C_{e}\right) \times V}{W}
\end{aligned}
$$


In these equations, $\mathrm{q}_{\mathrm{e}}(\mathrm{mg} / \mathrm{g})$ is adsorbed MCPA per adsorbent mass unit, $\mathrm{C}_{0}(\mathrm{mg} / \mathrm{L})$ is the initial concentration of MCPA at the solutions before the adsorption process, $C_{e}(\mathrm{mg} / \mathrm{L})$ is MCPA concentration at the equilibrium in the solution after adsorption, $\mathrm{V}(\mathrm{L})$ is the solution volume, and $\mathrm{W}(\mathrm{g})$ is the sorbent mass. Also, $C_{t}$ is the concentration at intervals of time ( $t$ ) and $R_{E}$ is changed MCPA concentration with respect to the time(27).

\subsection{Thermodynamics}

Adsorption thermodynamic was investigated by varying temperature from 298 to $318 \mathrm{~K}$.

The thermodynamic parameters, namely, enthalpy $(\Delta \mathrm{H})$, entropy $(\Delta S)$, and Gibbs free energy $(\Delta \mathrm{G})$ for adsorption of the selected pesticides onto PV/S-g-3D-GO/N were expressed by Van 't Hoff Eq. (3) and (4).

$$
\operatorname{In} K_{C}=\frac{-\Delta H}{R T}+\frac{\Delta S}{R}
$$

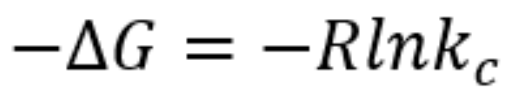

Where, $\mathrm{T}(\mathrm{K})$ and $\mathrm{R}(0.0083145 \mathrm{~kJ}$ mol-1 K-1) are temperature and the universal gas constant, respectively. $K C$ is the distribution coefficient and can be defined as $I n K C=q e / C e(28)$ 48.

\subsection{Regeneration of the adsorbent}

Regeneration studies were performed on (3D/GO/ $\left./ \mathrm{Fe}_{3} \mathrm{O}_{4}\right)$ by adding it in $20 \mathrm{mg} / \mathrm{L} \mathrm{MCPA}$ mixed with $5 \mathrm{~g} / \mathrm{L}$ of nano-adsorbent at $\mathrm{pH}: 3$ for $1 \mathrm{~h}$. After separating the sediment with the magnet and was mixed at 4000 rpm, the supernatant was used to determine the amount of remaining MCPA by a UV-Vis spectrophotometer (R1 run). The synthesized $3 \mathrm{D} / \mathrm{GO} / \mathrm{Fe}_{3} \mathrm{O}_{4}$ was washed with $5 \mathrm{ml}$ of methanol in ultrasonic apparatus for 2 minutes then was dried in an oven at $60^{\circ} \mathrm{C}$. This process was repeated 9 times(29).

\section{Results}

\subsection{FE-SEM analysis}

Morphology of the synthesized PV/S-g-3D-GO/N was determined by SEM (Scanning Electron Microscope) (Fig.1A). The obtained result shows that all the particles have porous spherical shape and this property helped to better adsorption properties. Moreover, the nanoparticle shows accumulated shape. In addition, it is demonstrated that the particle size is ranged from 40 to $80 \mathrm{~nm}$ and roughly, 
spherical shape, however, a slight aggregation phenomenon occurred. The TEM images show that the surfaces of $\mathrm{GO}$ are densely sheltered with uniformly distributed black colored $\mathrm{Fe}_{3} \mathrm{O}_{4}$ nanoparticle. The $\mathrm{Fe}_{3} \mathrm{O}_{4}$ nanoparticle are distributed on $\mathrm{GO}$. Moreover, there is not much agglomeration of $\mathrm{Fe}_{3} \mathrm{O}_{4}$ nanoparticles on the surface of graphene oxide. The $\mathrm{Fe}_{3} \mathrm{O}_{4}$ particle was founded on the edges of the sheets since carboxyl groups associated at the edges of GO (Fig. 1B).

\subsection{FTIR analysis}

The FTIR spectra of the $\mathrm{Fe}_{3} \mathrm{O}_{4}$ nanoparticle was shown in Fig.2A. The peak around $3387 \mathrm{~cm}-1$ and 634 $\mathrm{cm}^{-1}$ revealing the stretching vibration $\mathrm{Fe}_{3} \mathrm{O}_{4}$ group bonded with the $\mathrm{O}-\mathrm{H}$ group at $1626 \mathrm{~cm}^{-1}$ due to the adsorbed water on the surfaces(12). Fig. 2B is related to FTIR spectra of the 3D-GO/N. As it can clearly see the strong peak on the $3412 \mathrm{~cm}-1$ is observed, which is related to $3 \mathrm{D}-\mathrm{GO} / \mathrm{N}$ vibration, Moreover, the vibration band at 1626 and $634 \mathrm{~cm}^{-1}$ attributed to the $\mathrm{O}-\mathrm{H}$ and $\mathrm{Fe}_{3} \mathrm{O}_{4}$ groups and indicate that surface of nanoparticle have been successfully functioning. The FTIR spectrum of the PV/S-g-3D-GO/N confirms broad bands at $3423 \mathrm{~cm}^{-1}$ that are related to $\mathrm{O}-\mathrm{H}$ or N-H stretching vibration (Fig.2C). In addition, absorption bands of $\mathrm{OH}$ on the surface were observed. Another vibration peak at the $3022 \mathrm{~cm}^{-1}$ and 2916 $\mathrm{cm}^{-1}$ assigned to the $\mathrm{C}-\mathrm{H}$ bending mode of aromatic and aliphatic group in styrene, respectively. In addition, the peak at $1735 \mathrm{~cm}^{-1}$ was related to the $\mathrm{C}=0$ vibration and peak at $1596 \mathrm{~cm}^{-1}$ represented the C$\mathrm{C}$ aromatic bonds. The $\mathrm{CH}_{2}$ and $\mathrm{C}-0$ peaks appeared at $1446 \mathrm{~cm}^{-1}$ and $1022 \mathrm{~cm}^{-1}$, respectively. The sharp peak of $696 \mathrm{~cm}^{-1}$ also represented $\mathrm{Fe}_{3} \mathrm{O}_{4}$.

\subsection{XRD analysis}

According to obtained result from Fig.3 (A), 3D-GO/N (A) and the PV/S-g-3D-GO/N (B) was characterized by energy dispersive analysis of X-ray (EDX). The result of EDX spectrum prevalent that the planes (220), (311), (400), (511) and (440) which was related to $\mathrm{Fe}_{3} \mathrm{O}_{4}$ peaks (30). Moreover, the results show that the formation of the shoulder on its crystals will have no effect on the spectrum of magnetic particles(31). According to obtained result from Fig.3 (B), confirms the purity of $\mathrm{Fe}_{3} \mathrm{O}_{4}$ nano- magnetic particles, and the comparison between spectra shows the same structure in the two materials. The average crystallite size of the modified nano-adsorbent was calculated to be $12.55 \mathrm{~nm}$ using the Scherer-Debye equation.

\subsection{Magnetic properties measurement}

The Vibrating Sample Magnetometer (VSM) was used to determine the magnetic properties of the modified nano-adsorbent. As shown in Fig.4, the 3D-GO/N and PV/S-g-3D-GO/N spectra were S shape. The hysteresis loop of 3D-GO/N and PV/S-g-3D-GO/N is 70emu/g and 32emu/g, respectively. This reduction was due to the coating of $\mathrm{N}$-vinyl caprolactam and styrene on $3 \mathrm{D}-\mathrm{GO} / \mathrm{N}$, which acted as an adsorption agent and reduced the magnetic properties of the core as a shielding.

\subsection{Thermal gravimetric analysis (TGA)}


The thermal behavior of 3D-GO/N and PV/S-g-3D-GO/N was studied by thermal gravimetric analysis (TGA) from 0 to $600^{\circ} \mathrm{C}$. As shown in Fig. 6 and spectrum a, 3D-GO/N lost less than $1 \%$ of its weight due to the evaporation of surface water adsorbed on it at $150^{\circ} \mathrm{C}$. In general, weight loss about 80 to $150^{\circ} \mathrm{C}$ is due to the evaporation of water adsorbed onto the nanoparticle surfaces(32). Thereafter, no weight loss of up to $400{ }^{\circ} \mathrm{C}$ was observed, but at the higher temperatures, the weight loss was due to the burning of graphene oxide. For PV/S-g-3D-GO/N (Fig.5 A\&B), the weight loss was less than $1 \%$ due to the evaporation of water adsorbed onto the particle surface. The weight was constant up to $300{ }^{\circ} \mathrm{C}$ and then decreased due to the removal of the polymeric branches. At $400{ }^{\circ} \mathrm{C}$, weight loss was due to the burning of graphene oxide. The thermal gravimetric analysis showed that the polymeric branches have been successfully applied to 3D-GO/N.

\subsection{Effect of various parameters on the adsorption of MPCA}

\subsubsection{Effect of pH on adsorption}

$\mathrm{pH}$ is one of the most important parameters in the adsorption process, in this study the effect of different $\mathrm{pH}(2-8)$ on MCPA herbicide $(10 \mathrm{~g} / \mathrm{L})$ removal efficiency after 60 min contact time with PV/Sg-3D-GO/N $(3 \mathrm{~g})$ as an adsorbent was studied. As can be seen in Fig.6, the adsorption process was more efficient at acidic $\mathrm{pH}$ because MCPA had an acidic structure. At basic $\mathrm{pH}$, the herbicide was deformed into an ionic form and the adsorption decreased(25).

\subsubsection{Effect of adsorbent dose on the adsorption efficiency}

The effect of adsorbent dosage on adsorption efficiency was investigated. Obtained results show that adsorption efficiency has increased with increasing dosage of PV/S-g-3D-GO/N (Fig.7). However, unique properties of Graphene based adsorbent make it good candidate for remove different kind of contaminant from aquatic solution and different author reported different dosage for optimum removal efficiency that is different from /L0.1-12 mg for different pollution such as organic and inorganic pollutant (33). The reason is that when the dosage of the PV/S-g-3D-GO/N increased, the adsorption sites and functional groups on the adsorbent surface increased $(34,35)$ and lead to increasing removal efficiency. This could be due to the increase of active sites and functional groups at the nano-adsorbent surface.

\subsubsection{Effect of contact time on the adsorption efficiency}

The effect of contact time on the removal efficiency of MCPA at the optimal condition was studied. The results showed that as the contact time increased, the adsorption efficiency increased. Maximum removal efficiency was observed at the 300 min of contact time.

\subsubsection{Effect of temperature on the adsorption efficiency}

The effect of temperature on the MCPA removal by the PV/S-g-3D-GO/N was investigated by performing equilibrium adsorption studies at five different temperatures in the range of $30-55^{\circ} \mathrm{C}$. As shown in Fig.9, 
removal efficiency, increased with increasing temperature.

\subsubsection{Effect of initial MPCA concentration on the adsorption efficiency}

Figure.10 shows the adsorption efficiency of the PV/S-g-3D-GO/N for the removal of MPCA in different initial MPCA concentrations $\left(5-60 \mathrm{mg} \mathrm{L}^{-1}\right)$ at the optimal condition. The experiments, the parameters affecting the adsorption were stabilized at optimum values obtained from the previous steps $(\mathrm{pH}: 3$, of adsorbent dose: $5 \mathrm{~g} / \mathrm{L}$, temperature $50^{\circ} \mathrm{C}$, and contact time of $300 \mathrm{~min}$ ). The results show that the removal efficiency decreased with increasing concentration of herbicide in solution.

\subsection{Isotherm and kinetic studies of the adsorption}

Adsorption isotherms indicate the interaction between adsorbate and adsorbent in the liquid phase (free adsorbate solution) concentrations and the solid phase (adsorbent-attached solute) concentrations at constant temperature (36). Therefore, Langmuir, Freundlich, Temkin and Redlich-Peterson models were used in this study. In addition, the pseudo-first-order, pseudo-second-order was used for the evaluation kinetic of adsorption (Table.1). The obtained data reveal that the Langmuir model $\left(R^{2}=0.998\right)$ yielded best-fits to the experimental data(Table.2) that is maybe due to mono layer and the surface of the adsorbent surface is uniform. Therefore, there is no interaction between adsorbed molecules(37). The positive values of $\Delta S$ also indicated that the degree of freedom at the solid-liquid intermediate was increased during adsorption (Table.3)(38).

\subsection{Adsorbent regeneration}

Fig.11 illustrates the percentage change in adsorbent capability for the removal of herbicide after regeneration. As can be seen in the figure, the PV/Sg-3D-GO/N could operate up to twice usage with $100 \%$ efficiency. Then its efficiency was reduced but still could be used by up to seven times by more than $50 \%$ efficiency. Since the process of MCPA removal by adsorbents was based on surface adsorption, it is likely that the adsorbent may be used more frequently by changing the type of solvent used or increasing the washing time.

\subsection{Application of PV/S-g-3D-GO/N in the removal of MCPA herbicides from real samples}

After the adsorption process under optimum conditions, the residual MCPA concentration in the samples was below its detection limit $(1 \mathrm{ng} / \mathrm{L})$. These results showed that the synthesized adsorbent had excellent performance in removing MCPA from real samples and therefore impurities in water and wastewater samples did not significantly interfere with removal of the target contaminant.

\subsection{Comparison of PV/S-g-3D-GO/N adsorption capability with 3D-GO/N}

In order to determine the effectiveness of surface modifications and its branching on MCPA herbicide adsorption from aqueous solutions, PV/Sg-3D-GO/N coincidence with 3D-GO/N at optimum conditions $\left(\mathrm{pH}: 3\right.$, adsorbent dose: $5 \mathrm{~g} / \mathrm{L}$, temperature: $50{ }^{\circ} \mathrm{C}$, contact time: $300 \mathrm{~min}$ ) was used to remove herbicide 
from water. The results showed that the removal percentage of MCPA from water with PV/Sg-3D-GO/N was equal to $83.12 \pm 0.1$ while this value was in relation to the $3 D-G O / N$ of $25.66 \pm 7.37$. Therefore, if the $\mathrm{PV} / \mathrm{Sg}-3 \mathrm{D}-\mathrm{GO} / \mathrm{N}$ adsorption power of $100 \%$ is considered, the 3D-GO/N has $30 \%$ ability to remove MCPA from water. So it can be concluded that surface modification and branching of 3D-GO/N were effective in the adsorption of MCPA herbicides, which could be due to the accumulation of fine particles and the greater ability of styrene as herbicidal adsorption agent in the adsorbent surface.

\section{Discussion}

This study examined removal efficiency of 4-chloro-2-methyl-phenoxy acetic acid (MCPA) by 3D polymer nano-magnetic (PV/S-g-3D-GO/N). According to the obtained result, acidic condition ( $\mathrm{pH}: 3)$ was determined as an optimum $\mathrm{pH}$. These results were consistent with other relevant studies(25). although, some researchers have reported $\mathrm{pH}: 6$ as an optimal condition for the adsorption of phenoxy herbicides $(7,39)$. Different reported results can be related to the type of adsorbent and the different mechanisms of toxin by the adsorbent. Cao et al. adjusted the $\mathrm{pH}$ value of 2 for removal 2naphthoxyacetic acid by magnetic $\mathrm{GO}$ and demonstrated that the oxygen groups on the adsorption and analysts would be ionized at alkaline conditions so, reduce the extraction efficiency of synthesized adsorbent(40). The effect of adsorbent dosage shows that when the adsorption equilibrium was reached between the adsorbent and MCPA in the solution, the removal efficiency remained constant. Moreover, the high removal efficiency was observed at the $7 \mathrm{~g} \mathrm{~L}-1$ adsorbent dosage. As can be seen in Fig.8, the optimal removal process occurred when the dose of PV/S-g-3D-GO/N was equal to $5 \mathrm{~g} / \mathrm{L}(65 \%)$. Several studies have been carried out and achieved the same result(41, 42). In addition, further increase in contact time, there was little change in adsorption. Therefore, the optimum contact time between MCPA herbicide and PV/S-g-3D-GO/N was 300 min (Fig.8). Salman et. al has reported that adsorption efficiency of pesticide has decreased by increasing contact time. They are stating that higher number of vacant surface sites available for adsorption at the initial than the later stages and the repulsive forces existing between pesticide molecules on the absorbent surface and those in solution at the later stages(43). Removal efficiency, increased with increasing temperature. This is because as the temperature increased, the kinetic energy of the molecules increased, as a result, the collision between the herbicides particles and the adsorption sites on PV/S-g-3D-GO/N increased. On the other hand, N-vinyl caprolactam is a temperature-sensitive material and shrinks with increasing temperature(44), as a result, more interaction was created between MCPA and PV/S-g-3D- GO/N. Moreover, temperature can affect several aspects and has a positive influence by increasing the swelling capacity of an adsorbent, the mobility of MPCA molecules, the number of active sites, and the interaction between the adsorbate and adsorbent [40]. Therefore, an increase in the removal efficiency from $42 \%$ to $72 \%$ was observed. In addition, the optimum temperature for the removal efficiency $50^{\circ} \mathrm{C}$ was determined(45). In addition, results show that the gradual saturation of specific adsorption sites on the surface of PV/S-g-3D-GO/N as a result of the increased concentration of herbicides in the solution, whose result was a decrease in adsorption efficiency (46). It can be inferred that by increasing MPCA concentration the driving force was enhanced for the diffusion of MPCA adsorption. Therefore, active sites are occupied increasingly by influent MPCA 
and the $3 \mathrm{D} / \mathrm{GO} / \mathrm{Fe}_{3} \mathrm{O}_{4}$ as an adsorbent active sites saturated rapidly, so that the amount of adsorption decreased(47). Similar results were reported by Xu et al(48). It is possible that MCPA molecules interact with the $\pi-\pi$ interaction at the adsorbent surface [44]. According obtained data, maximum adsorption capacity $\left(\mathrm{q}_{\mathrm{m}}\right) 4.3 \mathrm{mg} / \mathrm{g}$ was reported. Moreover, The values of the empirical parameter show that $\mathrm{R}$ was 0.03 and it indicated optimal adsorption $(0 \leq R \leq 1)(49)$. In fact, different models of adsorption isotherms confirm each other. For example, in the Redlich - Peterson isotherm model, whenever $\mathrm{g}$ (1.0028) is close to 1, the data confirm the fit of the Langmuir model(50). Additionally, evaluate the thermodynamics of MCPA shows that the free energy $\left(\Delta G^{\circ}\right)$ values are negative, confirming that the adsorption is spontaneous and favorable thermodynamically(51). A positive value of $\Delta \mathrm{H}$ indicated that the adsorption process was endothermic and the adsorption capacity increased with increasing temperature.

\section{Conclusion}

In this study, a three-dimensional polymeric nano-magnetic adsorbent was prepared using iron oxide as the core, Graphene oxide as the 3D maker agent, $\mathrm{N}$-vinyl caprolactam as a temperature-sensitive monomer and styrene as the adsorbent agent. It was successfully used to remove MCPA herbicides from aquatic solution. The factors affecting the adsorption process as well as the optimum adsorption conditions were determined. The results showed that the maximum adsorption capacity of adsorbent $\left(\mathrm{q}_{\max }\right)$ was $4.36 \mathrm{mg} / \mathrm{g}$ at optimum conditions of $\mathrm{pH}=3$, contact time of $300 \mathrm{~min}$, adsorbent dose of $5 \mathrm{~g} / \mathrm{l}$ and the temperature of $50^{\circ} \mathrm{C}$. PV/S-g-3D-GO/N was also used to remove MCPA herbicides from real samples with $100 \%$ removal efficiency. Use of this adsorbent is recommended for the treatment of agricultural and industrial wastewater containing MCPA because of its ease of collection using a magnetic field and its regeneration by methanol. According to the results, this adsorbent is more effective in hot environments, so it can be used in hot environments such as southern Iran to remove the mentioned herbicide from contaminated water. The data of adsorption isotherm were in agreement with the Langmuir model $\left(R^{2}=0.998\right)$ and the adsorption kinetics followed the pseudo-second-order model $\left(R^{2}\right.$ $=0.999)$. Thermodynamic studies also showed that the MCPA adsorption process by PV/S-g-3D-GO/N was spontaneous $(\Delta \mathrm{G}<0)$ and endothermic $(\Delta \mathrm{H}>0)$ and increasing the temperature increased the adsorption capacity of the adsorbent.

\section{Declarations}

\section{Availability of data and materials}

The authors certify that this manuscript is the original work of the authors, all data collected during the study are presented in the manuscript, and no data from the study has been or will be published separately.

\section{Competing interests}


The authors declare that they have no conflict of interests.

\section{Authors' contributions}

All authors contributed and participated equally in the data collection, analysis, and interpretation. All authors critically reviewed, refined, and approved the manuscript.

\section{Funding}

The present study had no funding sources of any kind

\section{Acknowledgments}

The authors are grateful for the financial support of this project by the Research Council of Islamic Azad University, Tehran, Iran

\section{References}

1. R. Kalankesh L., Rodríguez-Couto S., and Zazouli M.A., Desalination and power generation of caspian sea by applying new designed microbial desalination cells in batch operation mode. Environmental Progress \& Sustainable Energy. 2019; 38. 13205.

2. Kalankesh L.R. and Zazouli M.A., Removal of salt from the Caspian Sea using a single-and doublelayer membrane microbial desalination cell in continuous-mode operation. Desalination and Water Treatment. 2019; 147. 83.

3. Shahamat Y.D., Asgharnia H., and Kalankesh L.R., Data on wastewater treatment plant by using wetland method, Babol, Iran. Data in Brief. 2018; 16. 1056.

4. Chen H., Zhang Z., Feng M., Liu W., Wang W., Yang Q., and Hu Y., Degradation of 2, 4dichlorophenoxyacetic acid in water by persulfate activated with FeS (mackinawite). Chem Eng J. 2017; 313. 498.

5. Esrafily A., Farzadkia M., Jonidi Jafari A., and Izanloo M., Removal of 2, 4-Dichlorophenoxyacetic acid herbicide from aqueous solutions by Functionalization nanoparticles magnetic: Equilibrium, kinetic and thermodynamic studies. Journal of North Khorasan University of Medical Sciences. 2018; 9. 1.

6. Pandiarajan A., Kamaraj R., Vasudevan S., and Vasudevan S., OPAC (orange peel activated carbon) derived from waste orange peel for the adsorption of chlorophenoxyacetic acid herbicides from water: adsorption isotherm, kinetic modelling and thermodynamic studies. Bioresour Technol. 2018; 261. 329.

7. Doczekalska B., Kuśmierek K., Świątkowski A., and Bartkowiak M., Adsorption of 2, 4-

dichlorophenoxyacetic acid and 4-chloro-2-metylphenoxyacetic acid onto activated carbons derived from various lignocellulosic materials. J Environ Sci Health B. 2018; 53. 290. 
8. Dehghani M., Nasseri S., and Karamimanesh M., Removal of 2, 4-Dichlorophenolyxacetic acid (2,4D) herbicide in the aqueous phase using modified granular activated carbon. J Environ Health Sci Eng. 2014; 12. 28.

9. Mansouri F., Khanjani N., and Pourmousa R., Forecasting ambient air pollutants by time series models in Kerman, Iran. Journal of School of Public Health and Institute of Public Health Research. $2013 ; 11.75$.

10. Kersten M., Tunega D., Georgieva I., Vlasova N., and Branscheid R., Adsorption of the herbicide 4chloro-2-methylphenoxyacetic acid (MCPA) by goethite. Environ Sci Technol. 2014; 48. 11803.

11. De Gisi S., Lofrano G., Grassi M., and Notarnicola M., Characteristics and adsorption capacities of low-cost sorbents for wastewater treatment: A review. Sustain Mater and Technol. 2016; 9. 10.

12. Bao S., Li K., Ning P., Peng J., Jin X., and Tang L., Highly effective removal of mercury and lead ions from wastewater by mercaptoamine-functionalised silica-coated magnetic nano-adsorbents: behaviours and mechanisms. Appl Surf Sci. 2017; 393. 457.

13. Ali A., Hira Zafar M.Z., Ul Haq I., Phull A.R., Ali J.S., and Hussain A., Synthesis, characterization, applications, and challenges of iron oxide nanoparticles. Nanotechnol Sci Appl. 2016; 9. 49.

14. Bhatnagar A. and Sillanpää M., Utilization of agro-industrial and municipal waste materials as potential adsorbents for water treatment-a review. Chem Eng J 2010; 157. 277.

15. Izanloo M., Esrafili A., Jafari A.J., Farzadkia M., Behbahani M., and Sobhi H.R., Application of a novel bi-functional nanoadsorbent for the simultaneous removal of inorganic and organic compounds: equilibrium, kinetic and thermodynamic studies. J Mol Liq. 2019; 273. 543.

16. Abbasi S., Ahmadpoor F., Imani M., and Ekrami-Kakhki M.-S., Synthesis of magnetic Fe304@ ZnO@ graphene oxide nanocomposite for photodegradation of organic dye pollutant. Int J Environ Anal Chem. 2020; 100. 225.

17. Sherlala A., Raman A., Bello M., and Asghar A., A review of the applications of organo-functionalized magnetic graphene oxide nanocomposites for heavy metal adsorption. Chemosphere. 2018; 193. 1004.

18. Azarova Y.A., Pestov A., and Bratskaya S.Y., Application of chitosan and its derivatives for solidphase extraction of metal and metalloid ions: a mini-review. Cellulose. 2016; 23. 2273.

19. Malakootian M., Ranandeh Kalankesh L., and Loloi M., Efficiency of hybrid nano particles of Tio2/Sio2 in removal of lead from paint industry effluents. J MUMS. 2013; 23. 244.

20. Iglesias A., López R., Gondar D., Antelo J., Fiol S., and Arce F., Adsorption of MCPA on goethite and humic acid-coated goethite. Chemosphere. 2010; 78. 1403.

21. Jensen P.H., Hansen H.C.B., Rasmussen J., and Jacobsen O.S., Sorption-controlled degradation kinetics of MCPA in soil. Environ sci technol. 2004; 38. 6662.

22. Shankar M., Anandan S., Venkatachalam N., Arabindoo B., and Murugesan V., Fine route for an efficient removal of 2, 4-dichlorophenoxyacetic acid $(2,4-\mathrm{D})$ by zeolite-supported TiO2. chemosphere. 2006; 63. 1014. 
23. Aksu Z. and Kabasakal E., Batch adsorption of 2, 4-dichlorophenoxy-acetic acid (2, 4-D) from aqueous solution by granular activated carbon. Sep Purif Technol. 2004; 35. 223.

24. Legrouri A., Lakraimi M., Barroug A., De Roy A., and Besse J., Removal of the herbicide 2, 4dichlorophenoxyacetate from water to zinc-aluminium-chloride layered double hydroxides. Water Res. 2005; 39. 3441.

25. Jenkins S., 1979 Annual Book of ASTM Standards, Part 31: Water: American Society for Testing and Materials: Philadelphia 1278 pp. \$38.00,1980, Pergamon.

26. Laurent S., Forge D., Port M., Roch A., Robic C., Vander Elst L., and Muller R.N., Magnetic iron oxide nanoparticles: synthesis, stabilization, vectorization, physicochemical characterizations, and biological applications. Chemical reviews. 2008; 108. 2064.

27. Malakootian M., Ranandeh Kalankesh L., and Loloi M., Efficiency of hybrid nano particles of Tio2/Sio2 in removal of lead from paint industry effluents. JMUMS. 2013; 23. 244.

28. Kalantary R.R., Azari A., Esrafili A., Yaghmaeian K., Moradi M., and Sharafi K., The survey of Malathion removal using magnetic graphene oxide nanocomposite as a novel adsorbent: thermodynamics, isotherms, and kinetic study. Desalination and Water Treatment. 2016; 57. 28460.

29. Saiphaneendra B., Saxena T., Singh S.A., Madras G., and Srivastava C., Synergistic effect of coexistence of hematite (a-Fe2O3) and magnetite ( $\mathrm{Fe} 3 \mathrm{O} 4)$ nanoparticles on graphene sheet for dye adsorption. J Environ Chem Eng. 2017; 5. 26.

30. Khansari A., Salavati-Niasari M., and Babaheydari A.K., Synthesis and characterization of Co 304 nanoparticles by thermal treatment process. J Clust Sci. 2012; 23. 557.

31. Salavati-Niasari M. and Khansari A., Synthesis and characterization of $\mathrm{C} 0304$ nanoparticles by a simple method. Comptes Rendus Chimie. 2014; 17. 352.

32. Tang Z., Wei Q., Lin T., Guo B., and Jia D., The use of a hybrid consisting of tubular clay and graphene as a reinforcement for elastomers. Rsc Advances. 2013; 3. 17057.

33. Chowdhury S. and Balasubramanian R., Recent advances in the use of graphene-family nanoadsorbents for removal of toxic pollutants from wastewater. Advances in colloid and interface science. 2014; 204. 35.

34. Aliannejadi S., Hassani A.H., Panahi H.A., and Borghei S.M., Fabrication and characterization of highbranched recyclable PAMAM dendrimer polymers on the modified magnetic nanoparticles for removing naphthalene from aqueous solutions. Microchem J. 2019; 145. 767.

35. Gupta $\mathrm{H}$. and Kumar R., Removal of PAH anthracene from aqueous media using banana peel activated carbon. Int Res J Environ Sci. 2016; 4. 0109.

36. Bajpai S., Chand N., and Mahendra M., The adsorptive removal of cationic dye from aqueous solution using poly (methacrylic acid) Hydrogels: Part-I. equlibrium studies. Int J Environ Sci. 2012; 2. 1609.

37. Schmid R. and Reilley C.N., A rapid electrochemical method for the determination of metal chelate stability constants. J American Chemical Society. 1956; 78. 5513. 
38. Uslu G. and Tanyol M., Equilibrium and thermodynamic parameters of single and binary mixture biosorption of lead (II) and copper (II) ions onto Pseudomonas putida: effect of temperature. J Hazard Mater. 2006; 135. 87.

39. Kazak O., Eker Y.R., Akin I., Bingol H., and Tor A., Green preparation of a novel red mud@ carbon composite and its application for adsorption of 2, 4-dichlorophenoxyacetic acid from aqueous solution. Environ Sci Pollut Res. 2017; 24. 23057.

40. Cao S., Chen J., Lai G., Xi C., Li X., Zhang L., Wang G., and Chen Z., A high efficient adsorbent for plant growth regulators based on ionic liquid and $\beta$-cyclodextrin functionalized magnetic graphene oxide. Talanta. 2019; 194. 14.

41. Saeidi M., Naeimi A., and Komeili M., Magnetite nanoparticles coated with methoxy polyethylene glycol as an efficient adsorbent of diazinon pesticide from water. Advances in Environmental Technology. 2016; 2. 25.

42. Moussavi G., Hosseini H., and Alahabadi A., The investigation of diazinon pesticide removal from contaminated water by adsorption onto NH4Cl-induced activated carbon. Chem Eng J. 2013; 214. 172.

43. Salman J., Njoku V., and Hameed B., Adsorption of pesticides from aqueous solution onto banana stalk activated carbon. Chem Eng J. 2011; 174. 41.

44. Ramos J., Imaz A., and Forcada J., Temperature-sensitive nanogels: poly (N-vinylcaprolactam) versus poly (N-isopropylacrylamide). Polym Chem. 2012; 3. 852.

45. Constantin M., Asmarandei I., Harabagiu V., Ghimici L., Ascenzi P., and Fundueanu G., Removal of anionic dyes from aqueous solutions by an ion-exchanger based on pullulan microspheres. Carbohydr Polym. 2013; 91. 74.

46. Saber-Samandari S., Gazi M., and Yilmaz O., Synthesis and characterization of chitosan-graft-poly (N-allyl maleamic acid) hydrogel membrane. Water Air Soil Pollut 2013; 224. 1624.

47. Amiri M.J., Abedi-Koupai J., and Eslamian S., Adsorption of $\mathrm{Hg}$ (II) and Pb (II) ions by nanoscale zero valent iron supported on ostrich bone ash in a fixed-bed column system. Water Sci Technol 2017; 76. 671.

48. Xu L., Wang S., Zhou J., Deng H., and Frost R.L., Column adsorption of 2-naphthol from aqueous solution using carbon nanotube-based composite adsorbent. Chem Eng J. 2018; 335. 450.

49. Saad M.E.K., Khiari R., Elaloui E., and Moussaoui Y., Adsorption of anthracene using activated carbon and Posidonia oceanica. Arabian Journal of Chemistry. 2014; 7. 109.

50. Belhachemi M. and Addoun F., Comparative adsorption isotherms and modeling of methylene blue onto activated carbons. Appl Water Sci. 2011; 1. 111.

51. Eser A., Tirtom V.N., Aydemir T., Becerik S., and Dinçer A., Removal of nickel (II) ions by histidine modified chitosan beads. Chem Eng J. 2012; 210. 590.

\section{Tables}


Table 1 - kinetic parameter for MCPA adsorption by the PV/S-g-3D-GO/N

\begin{tabular}{|lll|}
\hline Kinetic model & Parameter & Quantity \\
\hline pseudo first order & $\mathrm{q}_{\mathrm{e}}(\mathrm{mg} / \mathrm{g})$ & 0.6283 \\
& $\mathrm{~K}_{1}\left(\mathrm{~min}^{-1}\right)$ & 0.00783 \\
& $\mathrm{R}^{2}$ & 0.9524 \\
\hline pseudo-second-order & $\mathrm{q}_{\mathrm{e}}(\mathrm{mg} / \mathrm{g})$ & 4.2123 \\
& $\mathrm{~K}_{2}(\mathrm{~g} / \mathrm{mg} / \mathrm{min})$ & 0.07856 \\
& $\mathrm{R}^{2}$ & 0.9996 \\
\hline intraparticle diffusion & $\mathrm{ki}\left(\mathrm{min}{ }^{\wedge} 0.5\right)$ & 0.0856 \\
& $\mathrm{C}(\mathrm{mg} / \mathrm{g})$ & 3.3343 \\
& $\mathrm{R}^{2}$ & 0.9878 \\
\hline
\end{tabular}

Table 2 - Adsorption isotherm parameters for MCPA sorption by the PV/S-g-3D-GO/N 


\begin{tabular}{|lll|}
\hline Isoterm model & Parameter & Quantity \\
\hline Langmuir & $\mathrm{q}_{\max }(\mathrm{mg} / \mathrm{g})$ & 4.36 \\
& $\mathrm{k}_{\mathrm{L}}(\mathrm{L} / \mathrm{mg})$ & 0.53 \\
& $\mathrm{R}_{\mathrm{L}}$ & 0.03 \\
\hline Freundlich & $\mathrm{R}^{2}$ & 0.997 \\
\hline & $\mathrm{Kf}[(\mathrm{mg} / \mathrm{g})(\mathrm{L} / \mathrm{mg}) 1 / \mathrm{n}]$ & 1.77 \\
\hline & $\mathrm{n}$ & 3.8 \\
\hline Temkin & $\mathrm{R}^{2}$ & 0.946 \\
\hline & $\mathrm{A}(\mathrm{L} / \mathrm{g})$ & 9.62 \\
& $\mathrm{~B}$ & 0.74 \\
\hline & $\mathrm{b}(\mathrm{j} / \mathrm{mol})$ & 3638 \\
\hline Redlich-Peterson & $\mathrm{R}$ & 0.969 \\
\hline & $\mathrm{B}$ & 4.87 \\
\hline $\mathrm{g}$ & 1.276 \\
\hline $\mathrm{R}^{2}$ & 1.002 \\
\hline & 0.990 \\
\hline
\end{tabular}

Table 3 -Thermodynamic parameters of MCPA onto the PV/S-g-3D-GO/N

\begin{tabular}{|lllll|}
\hline $\mathrm{S}(\mathrm{j} / \mathrm{mol} . \mathrm{K}) \Delta$ & $\mathrm{H}(\mathrm{kj} / \mathrm{mol}) \Delta$ & $\mathrm{G}(\mathrm{kj} / \mathrm{mol}) \Delta$ & $\mathrm{K}_{\mathrm{L}}(\mathrm{L} / \mathrm{g})$ & $\mathrm{T}(\mathrm{K})$ \\
\hline 160.8593 & 35.05099 & -13.7135 & 226.554 & 303.15 \\
& & -15.3221 & 372.853 & 313.15 \\
& & -16.9307 & 535.1389 & 323.15 \\
\hline
\end{tabular}

Figures 

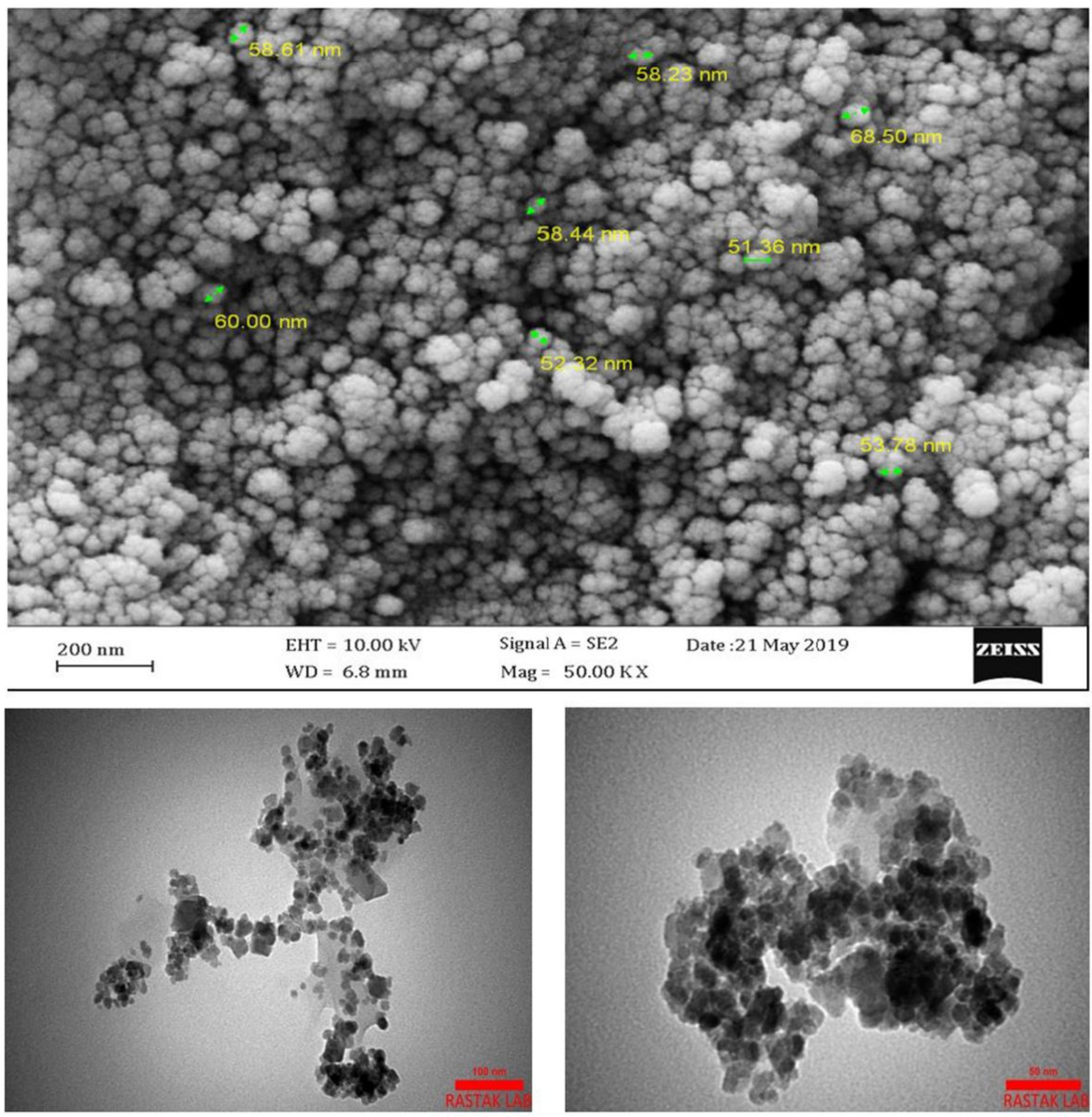

\section{Figure 1}

SEM of the synthesized PV/S-g-3D-GO/N (A), TEM images of GO-Fe304 (B) 

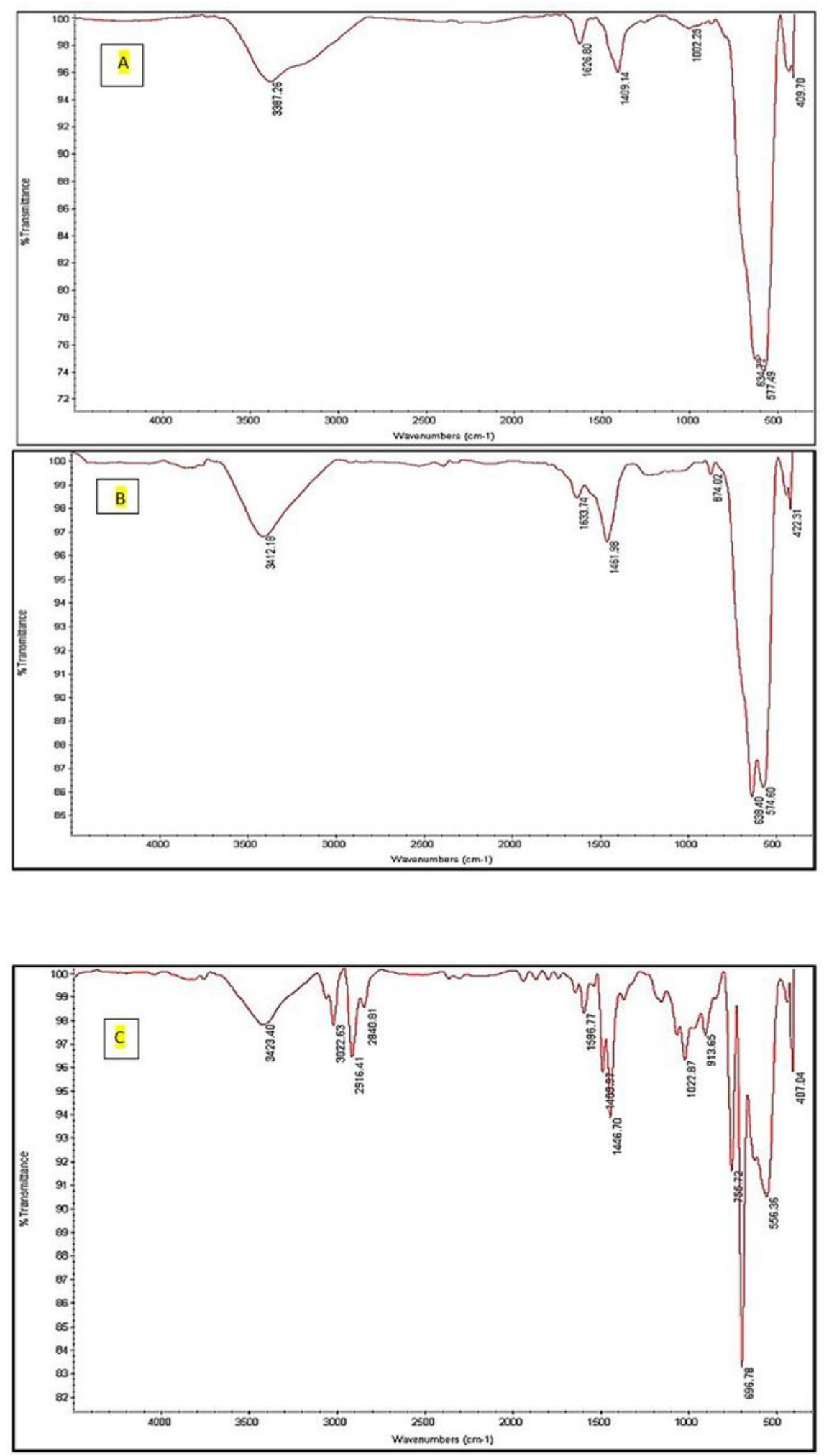

Figure 2

FT-IR spectra of (A) Fe304,, (B) Fe304@GO, (C) the synthesized 3D/GO/Fe304 


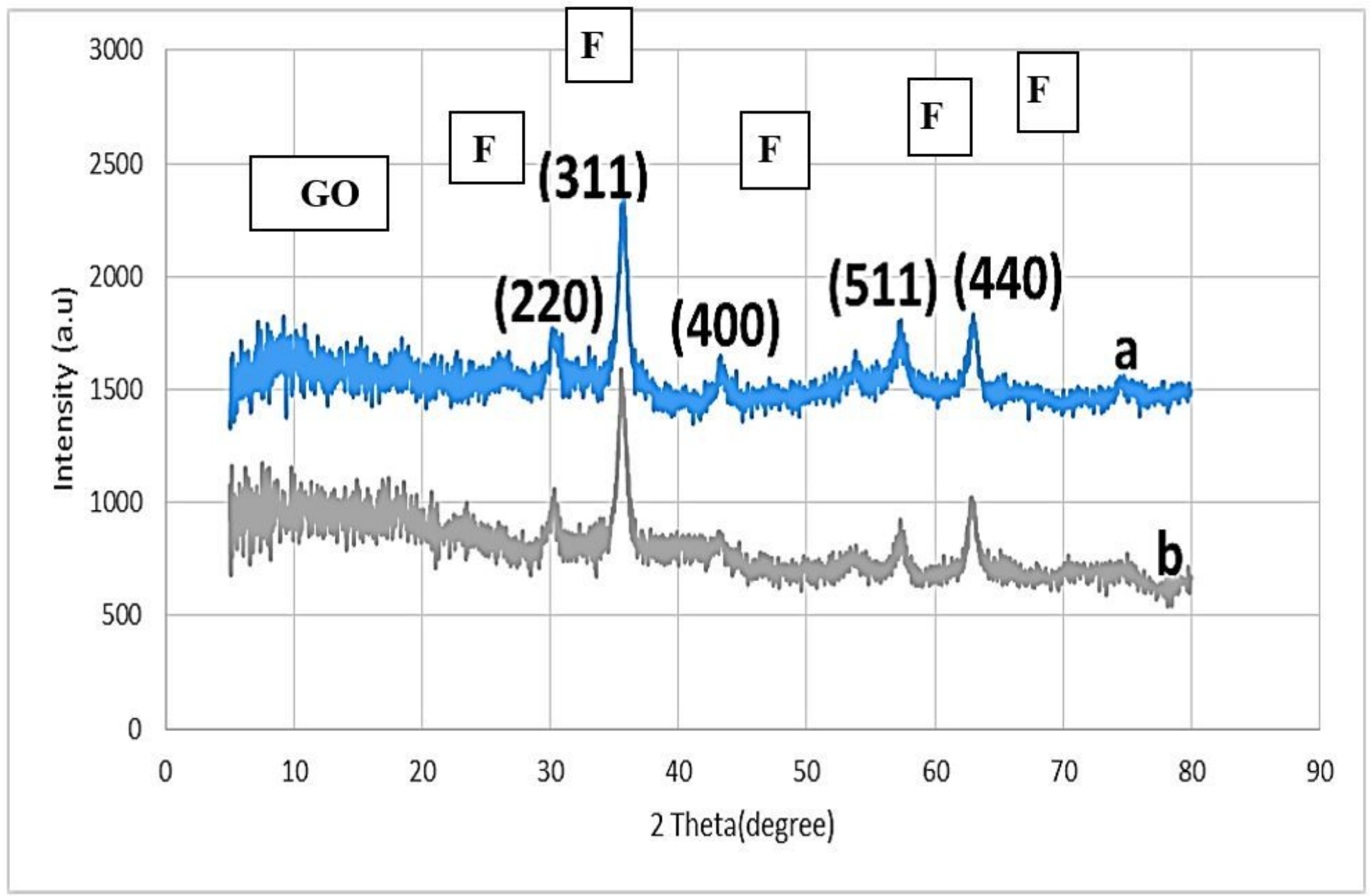

Figure 3

XRD pattern of A) Fe304@GO and B) the synthesized 3D/GO/Fe304 


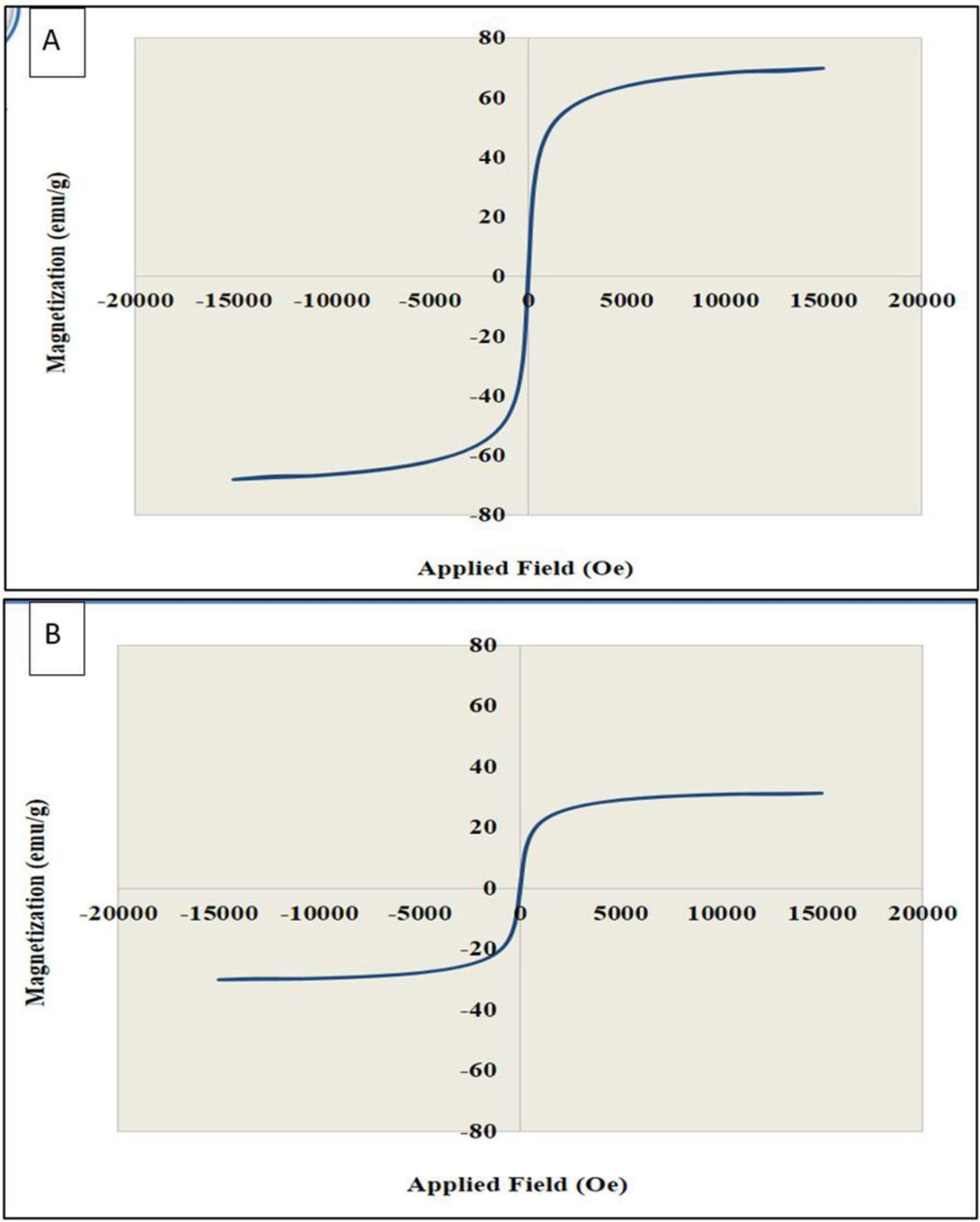

Figure 4

VSM of Fe304@GO (A) and the synthesized 3D/GO/Fe304 (B) 

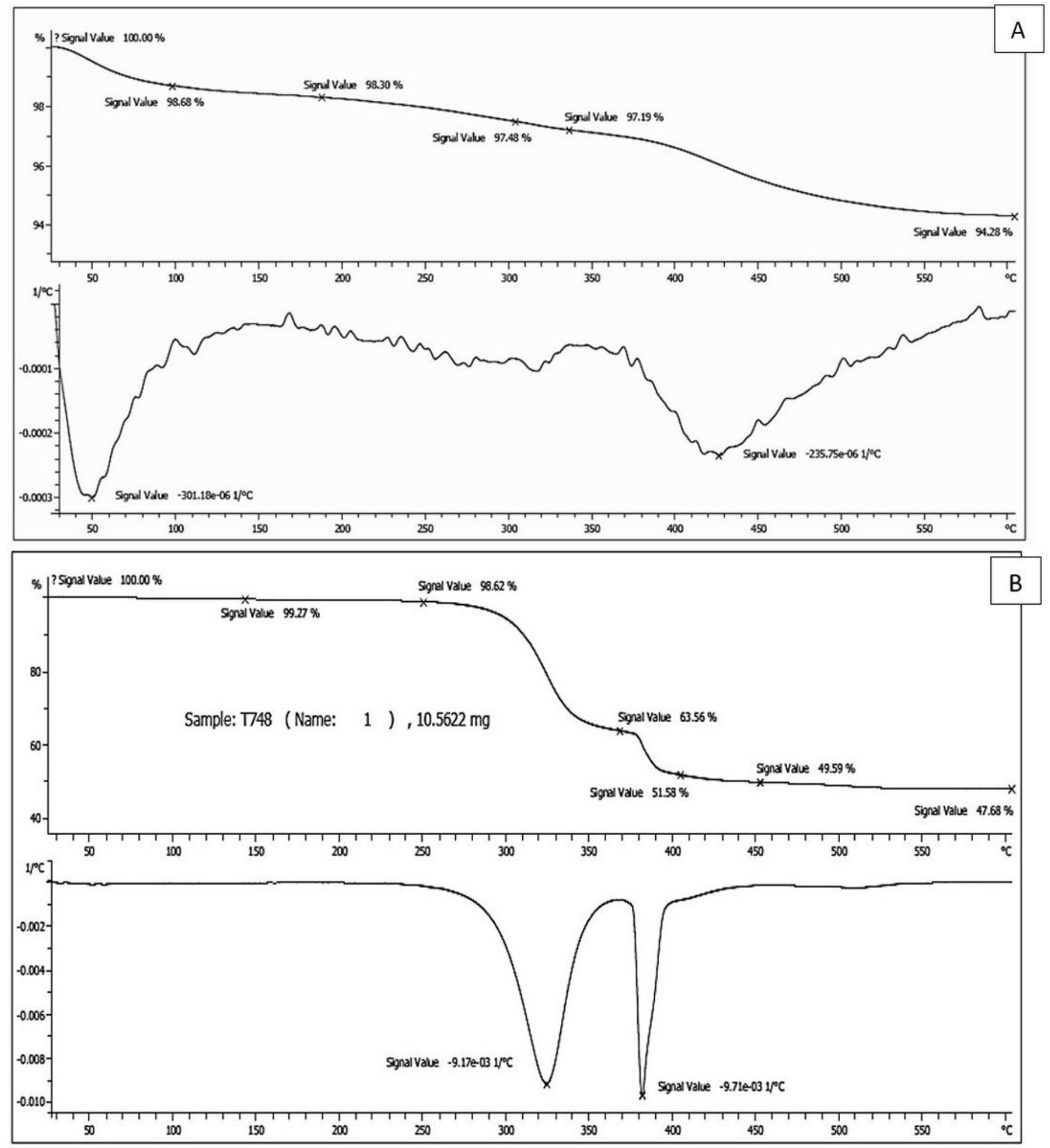

Figure 5

TGA of Fe304@G0 (A) and the synthesized 3D/GO/Fe304 (B) 


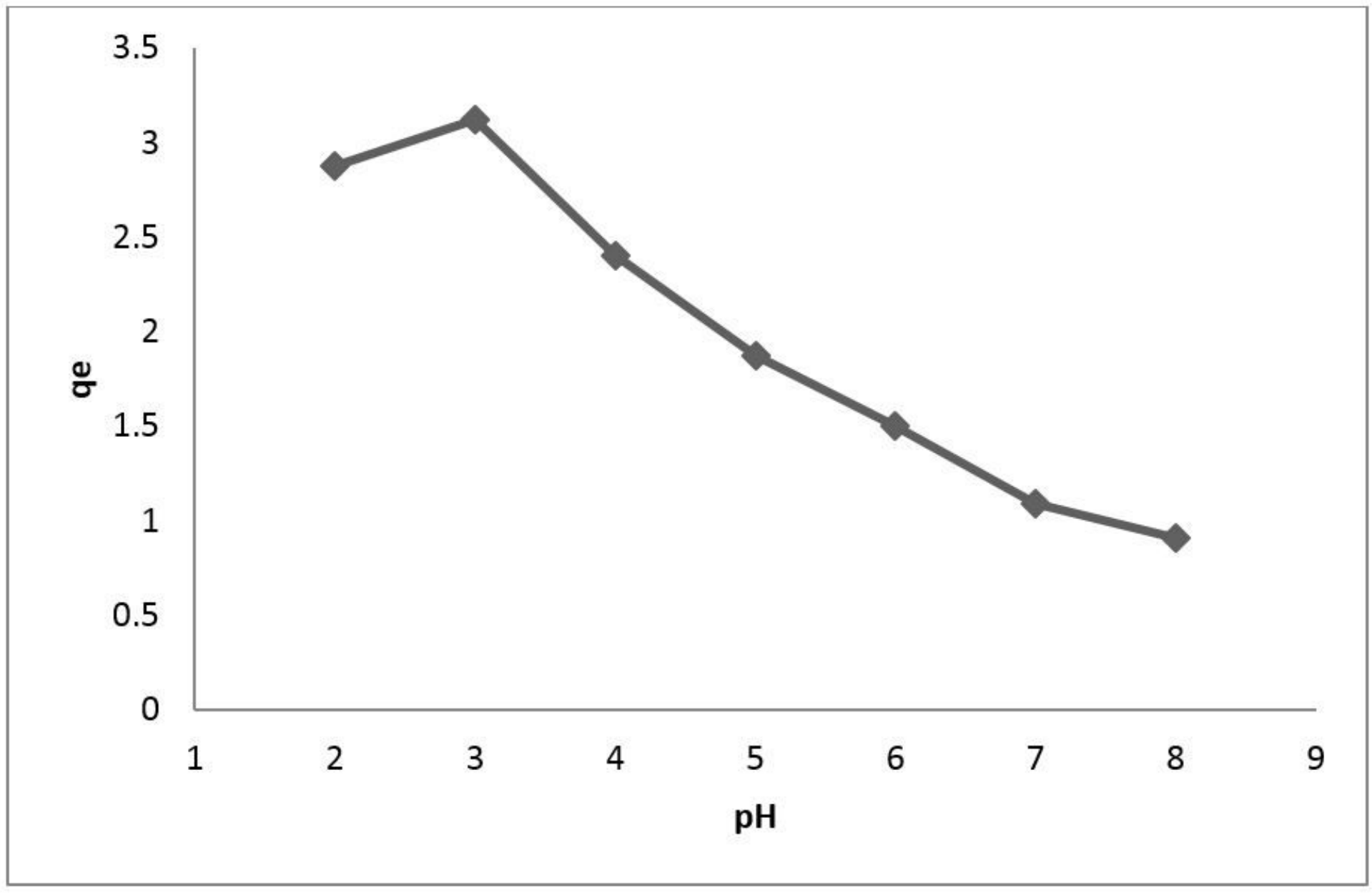

Figure 6

Effect of pH on MCPA removal by the PV/S-g-3D-GO/N (contact time: 60 min, MCPA initial concentration: $10 \mathrm{~g}$, adsorbent dosage: $3 \mathrm{~g}$ ) 


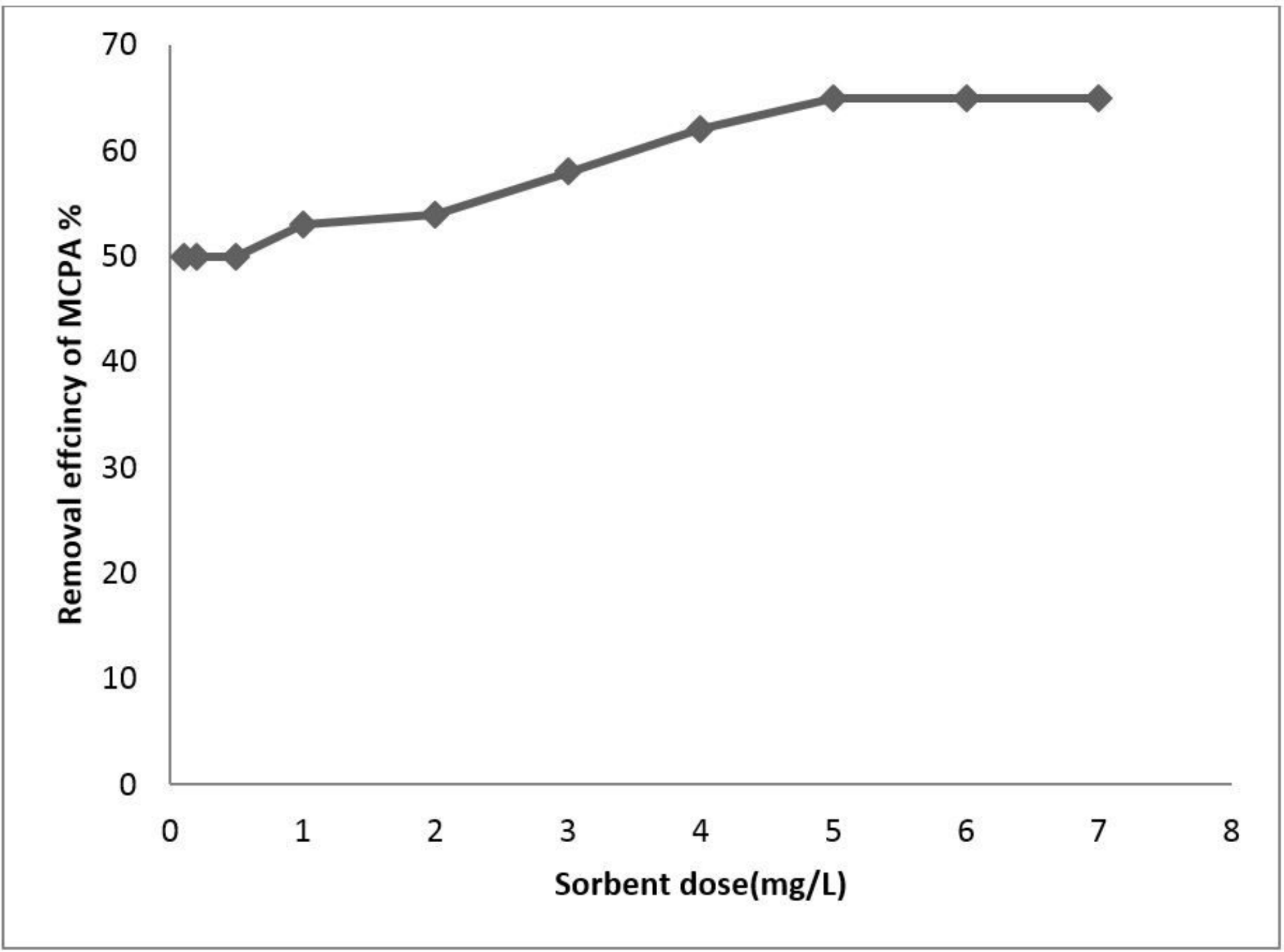

Figure 7

Effect of different adsorbent dosage on removal efficiency ( $\mathrm{pH}: 3, \mathrm{MCP}$ initial concentration: $10 \mathrm{~g} / \mathrm{L}$, contact time: $60 \mathrm{~min}$ ) 


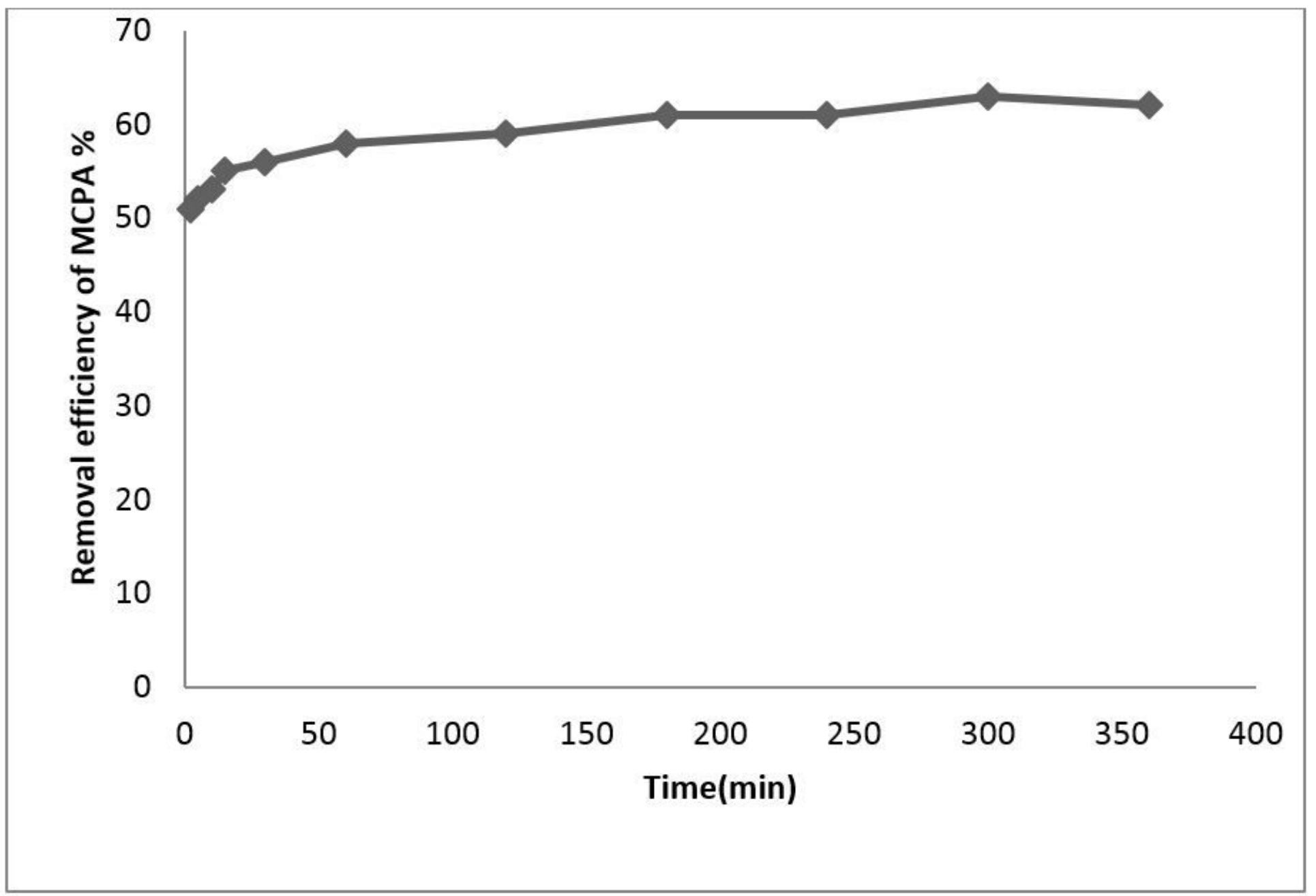

Figure 8

Effect of contacting time on the adsorption efficiency (adsorbent dosage: 10g, initial MCPA concentration: $10 \mathrm{~g} / \mathrm{L}$, and $\mathrm{pH}: 3$ ) 


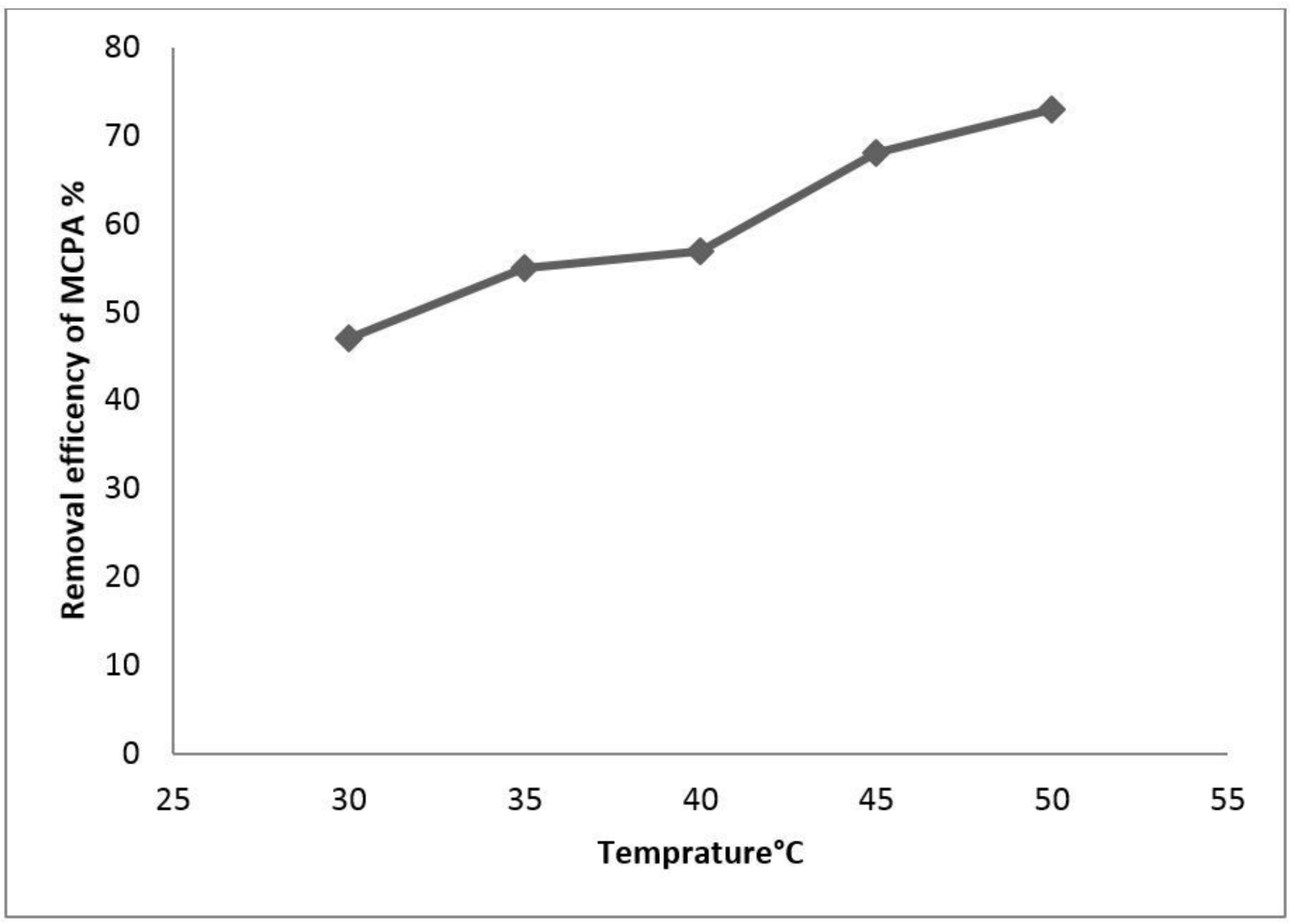

\section{Figure 9}

Effect of temperature in removal efficiency of MCPA $(\mathrm{pH}: 3$, adsorbent dosage: $3 \mathrm{~g} / \mathrm{L}$, initial concentration of MCPA :10 mg/L, contact time: $300 \mathrm{~min}$ ) 


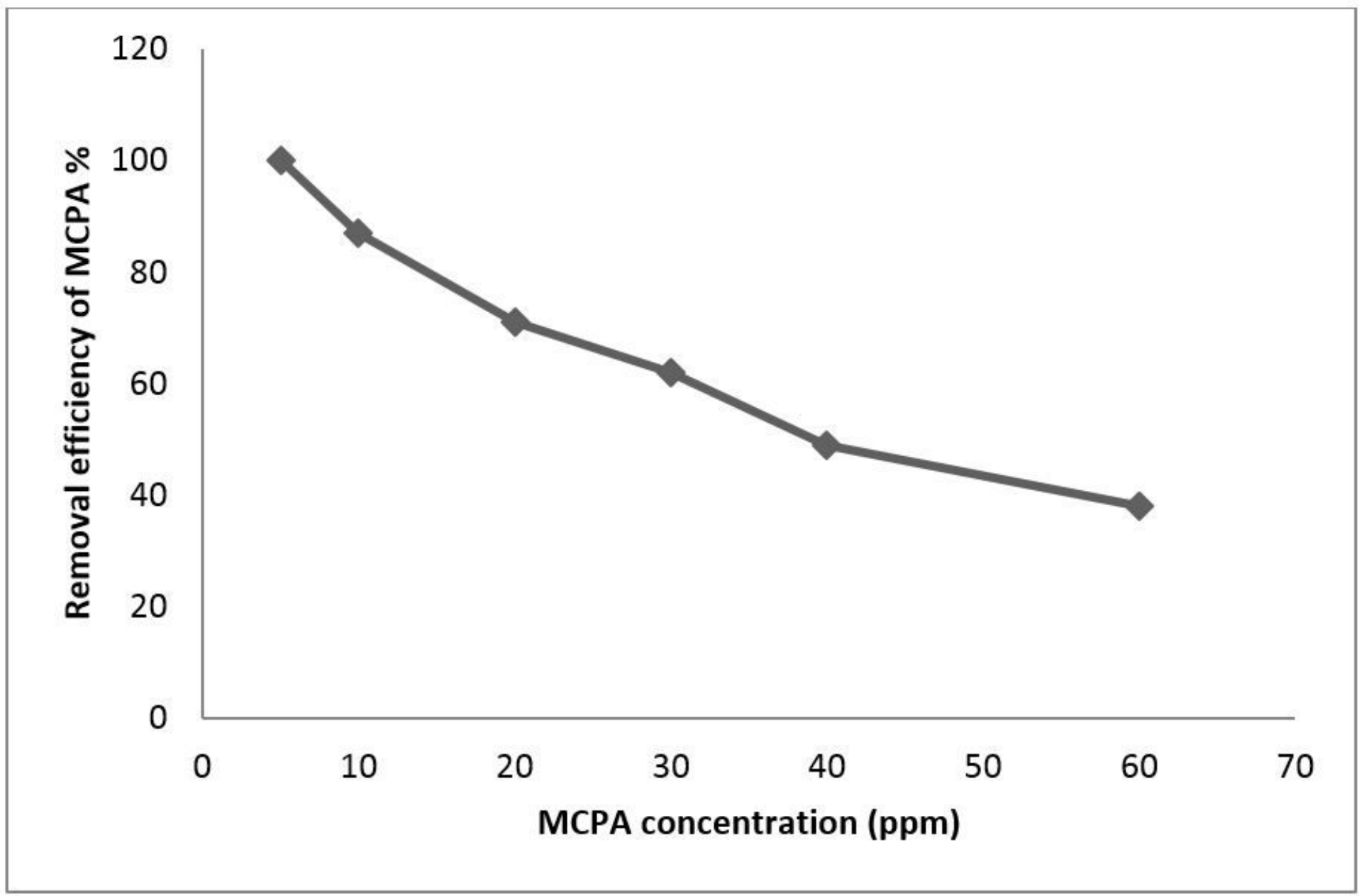

Figure 10

Effect of initial concentration of MCPA on adsorption $\left(\mathrm{pH}: 3\right.$, of adsorbent dose: $3 \mathrm{~g} / \mathrm{L}$, temperature: $50^{\circ} \mathrm{C}$, and contact time: $300 \mathrm{~min}$ ) 


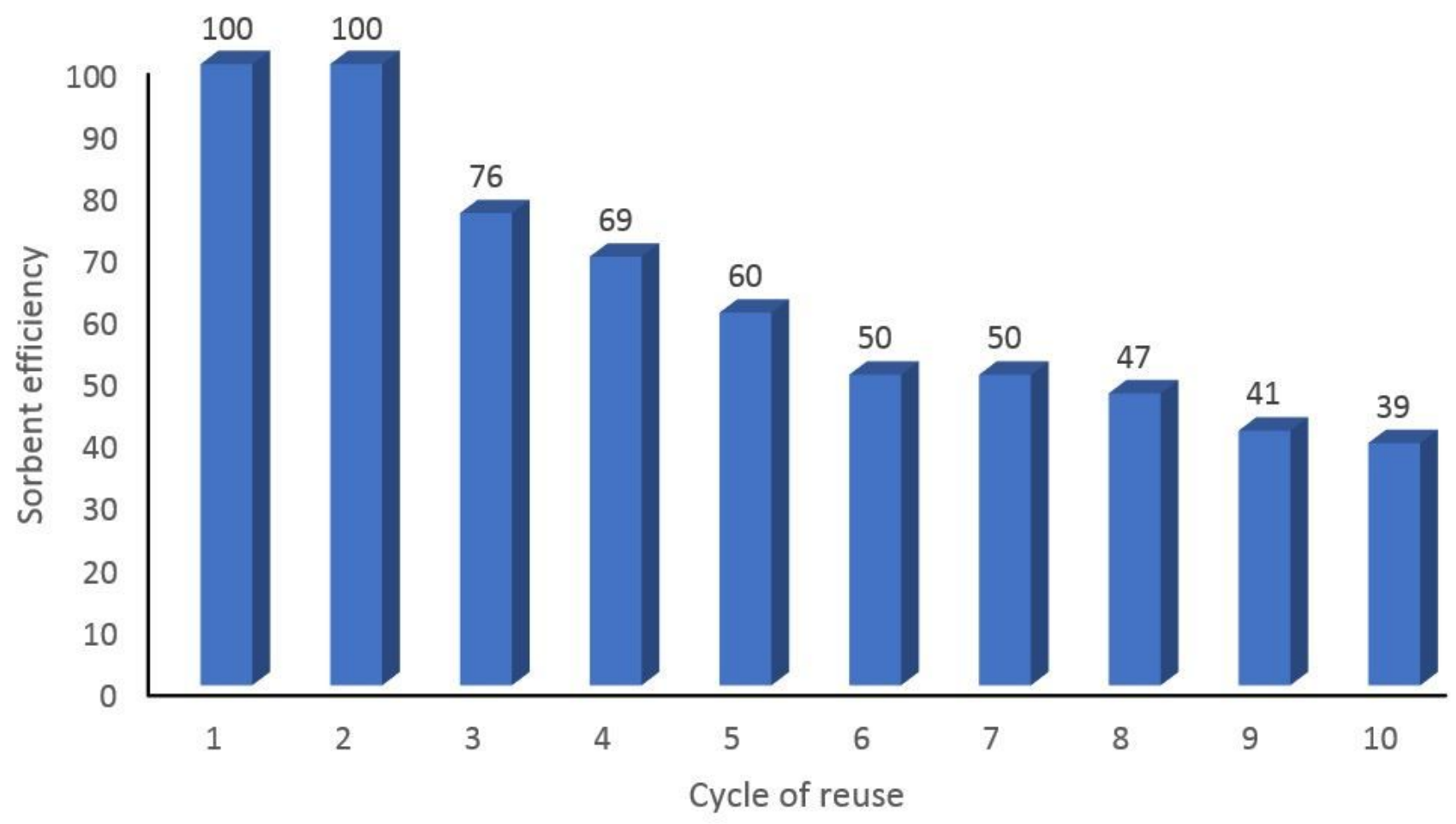

Figure 11

The PV/S-g-3D-GO/N efficiency after regeneration 